\title{
Evalution of Dataminig for Prediction Techniques Based on Weka Tool
}

\author{
S. Yogalakshmi, S. Swetha, G. Ayyappan
}

\begin{abstract}
Data mining is a famous technological innovation that converts piles of data into beneficial knowledge, which can assist the data proprietors/users make knowledgeable choices and take clever movements for their personal advantage. In unique terms, facts mining looks for hidden patterns amongst widespread sets of data that may assist to apprehend, expect, and guide destiny conduct. A greater technical explanation: information mining is the set of methodologies utilized in reading data from diverse dimensions and perspectives, finding formerly unknown hidden styles, classifying and grouping the information and summarizing the diagnosed relationships. The elements of facts mining consist of extraction, transformation, and loading of data onto the statistics warehouse device, handling information in a multidimensional database gadget, offering get right of entry to to commercial enterprise analysts and it experts, reading the records with the aid of tools, and supplying the data in a useful layout, inclusive of a graph or desk. That is completed with the aid of identifying courting using classes, clusters, associations, and sequential patterns by using the use of statistical analysis, gadget leaning and neural networks
\end{abstract}

Keywords: extraction, transformation, Open Source Tools, data preparation

\section{INTRODUCTION}

This area presents presentation of this exploration work. Information can produce income. It is a significant monetary resource of a venture. Organizations can utilize information digging for learning revelation and investigation of accessible information. This can enable them to anticipate future patterns, comprehend client's inclinations and buy propensities, and direct a valuable market investigation. They would then be able to manufacture models dependent on authentic information examples and collect more from focused market battles just as strategize increasingly gainful selling approaches. Information mining encourages endeavors to settle on educated business choices, upgrades business insight, in this manner improving the organization's income and decreasing cost overheads. Information mining is likewise valuable in discovering information peculiarity designs that are basic in extortion location and zones of

Revised Manuscript Received on July 22, 2019.

S. Yogalakshmi, Department of Information Technology, Bharath Institute of Higher Education and Research, Tambaram, India.

S. Swetha,Department of Information Technology, Bharath Institute of Higher Education and Research, Tambaram, India.

Dr.G.Ayyappan, Department of Information Technology, Bharath Institute of Higher Education and Research, Tambaram, India powerless or wrong information resemblance/adjustment. Getting the assistance of experienced information passage specialist co-ops in the beginning periods of information the board can make the consequent information mining simpler.

In this paper presents segment 2 of this paper clarifies the [2 ],[4],[6]detail on the related works. In segment 3 exhibits the materials and techniques received and segment 4 introduces the subtleties of the examinations and talks. At long last area 5 finishes up the paper by sharing our surmisings and feasible arrangements. [1],[3],[5]

\section{A. DATA MINING TECHNIQUES}

The work of art of insights mining has been constantly advancing. There are some of current and instinctive systems which have risen that fine-music measurements mining thoughts in an offer to show organizations more prominent complete discernment into their own information with helpful predetermination improvements. Numerous procedures are procured by means of the information mining authorities, some of which can be listed underneath: [7],[ 9] ,[11]

Seeking for Incomplete Records:

Information mining depends on the genuine records present, in this way if information is deficient, the outcomes may be totally off-mark. Subsequently, it's far crucial to have the insight to sniff out inadequate records if feasible. Systems including self-sorting out maps, help to guide missing records based absolutely by method for imagining the form of multi-dimensional complex information. Multi-venture concentrating for lacking sources of info, wherein one present and legitimate data set alongside its techniques is in correlation with each other very much coordinated however fragmented records set is one way to are searching for out such insights. Multi-dimensional preceptors utilizing astute calculations to construct ascription strategies can manage deficient properties of data. [8],[10],[12]

\section{Dynamic Data dashboards:}

That is a scoreboard, on a chief or director's PC, encouraged with real time from data as it streams inside and outside of different databases inside the association's environment. Data mining methodologies are connected to present stay understanding and observing of actualities to the partners.

Database evaluation: 
Databases save key information in a reliant configuration, so calculations fabricated the utilization of their own language (alongside sq. Macros) to discover concealed styles inside arranged data is generally valuable. Those calculations are once in a while in-incorporated with the data streams, e.G. Firmly combined with client characterized highlights, and the discoveries provided in a prepared to-allude to record with important assessment. [13], [15] ,[ 17]

A magnificent methodology is to have the photograph dump of data from a huge database in a store document whenever after which investigate it moreover. Further, records mining calculations ought to have the option to haul out information from mutiple, heterogeneous databases and expect changing over patterns. [14],[ 16], [18]

\section{Textual Content evaluation:}

This idea might be useful to routinely discover designs inside the content installed in swarms of printed substance records, word-handled archives, pdfs, and introduction reports. The literary substance preparing calculations can for example, discover rehashed concentrates of information, which is entirely helpful inside the distributing undertaking or colleges for following copyright infringement. [19],[21],[23]

\section{Efficient, complex and relational statistics:}

A measurements distribution center or enormous insights shops must be bolstered with intuitive and question-essentially based certainties digging for a wide range of realities mining capacities comprising of sort, bunching, affiliation, expectation. OLAP (on-line expository preparing) is one such valuable strategy. Different models that encourage intelligent actualities mining are perusing charts, mix questioning, picture arrangement, meta-rule guided mining, change randomization, and multidimensional factual assessment. [20],[ 22], [24]

\section{Relevance and Scalability in selected data mining algorithms:}

While picking or picking data mining calculations, it is imperative that organizations hold in musings the endeavor pertinence of the forecasts and the versatility to diminish charges in fate. Different calculations must almost certainly be executed in parallel for time execution, autonomously and without meddling with the transnational venture bundles, especially time-significant ones. There should be help to comprise of svms on huge scale. [25],[27],[29]

\section{Popular Tools for data mining:}

There are various readymade apparatus to be had for insights mining inside the commercial center these days. Some of those have ordinary functionalities bundled inside, with arrangements to highlight on capacity by utilizing helping working of business undertaking specific examination and insight. [26],[28],[30]

\section{Rapid Miner:}

That is well known since it's far a readymade, open supply, no-coding required programming, which gives progressed investigation. Written in java, it conveys multifaceted records mining capacities which incorporate measurements pre-handling, perception, prescient examination, and can be effectively coordinated with weka and R-Tool to quickly give designs from contents written in the previous. [31],[33],[35]

\section{II.MATERIALS AND METHODS}

\section{Data Mining Implementation Process}

Data Mining implementation process includes: Business undertaking data: on this portion, endeavor and records-mining wants are introduced. [32],[34],[36]

In the first place, you need to secure business and supporter goals.Take stock of the cutting edge data mining circumstance. Thing in assets, suspicion, requirements, and other noteworthy components into your evaluation. Utilizing undertaking targets and current situation, diagram your measurements mining objectives. A wonderful insights mining plan is exceptionally particular and should be created to achieve every business undertaking and data mining objectives. [37],[39],[41]

Information aptitude: in this area, mental stability investigate realities is done to check whether its fitting for the measurements mining wants. In the first place, actualities is amassed from more than one information advantages for be had inside the organization. Those data sources may likewise incorporate more than one databases, level filer or records $3 \mathrm{D}$ shapes. There are inconveniences like thing coordinating and diagram mix which can stand up at some phase in records combination method. It's miles a really entangled and confused methodology as data from different assets not liable to sound effectively. Realities guidance: in this stage, records is made creation arranged. The information guidance procedure devours around ninety $\%$ of the season of the undertaking. The measurements from explicit sources should be chosen, cleaned off, changed, designed, anonymized, and constructed (whenever required). [38],[40]

Information purging is a system to "smooth" the information with the guide of smoothing uproarious records and filling in lacking qualities. For instance, for a client socioeconomics profile, age data is absent. The data is deficient and must be packed. Sometimes, there could be information exceptions. For example, age has an expense 300. Insights may be conflicting. For instance, name of the customer is particular in unmistakable tables. Measurements change tasks substitute the realities to make it valuable in records mining. Following change can be actualized, insights change: records change tasks would contribute nearer to the accomplishment of the mining method. Smoothing: it empowers to expel clamor from the measurements. Conglomeration: predicts or accumulation tasks are done to the data. I.E., the week by week deals records is totaled to figure the month-to-month and consistently by and large.

Speculation: in this progression, low-organize measurements is changed by methods for better-arrange norms with the help of idea chains of command. For instance, the city is changed with the guide of the province. 
Standardization: standardization completed while the trademark insights are scaled up o downsized. Characteristic development: those qualities are fabricated and secured the given arrangement of properties supportive for records mining. The consequence of this technique is a last insights set that might be used in displaying. Displaying: in this fragment, scientific styles are utilized to decide records designs. In view of on the business venture goals, fitting demonstrating methodologies should be chosen for the readied dataset. Make a situation to test check the main rate and legitimacy of the model. Run the model on the readied dataset. Impacts should be surveyed by method for all partners to verify that variant can meet records mining objectives. Appraisal: on this fragment, designs recognized are assessed contrary to the business destinations. Results created by means of the data mining model should be assessed contrary to the business undertaking destinations. Picking up business know-how is an iterative framework. As a general rule, even as seeing, new advertisement venture necessities can be raised because of information mining. A move or no-cross determination is taken to move the rendition inside the arrangement stage.

Organization: in the sending section, you convey your certainties mining disclosures to typical business undertaking tasks. The expertise or actualities saw throughout insights mining way should be made smooth to perceive for non-specialized partners. A top to bottom sending plan, for transportation, protection, and observing of information mining disclosures is made. An absolute last endeavor archive is made with exercises found and key stories all through the endeavor. This empowers to improve the business' venture arrangement. Information Mining Techniques

\section{A. Challenges of Implementation of Data mine:}

Talented experts need to define the records mining questions. Overfitting: because of little size tutoring database, a model probably won't suit future states. Information mining wishes enormous databases which at times are difficult to control. Endeavor practices may likewise need to be changed to decide to apply the insights uncovered. On the off chance that the records set are not various, data mining impacts probably won't be exact. Mix certainties needed from heterogeneous databases and worldwide realities structures may be unpredictable

\section{EXPERIMENTS AND DISCUSSION}

In this section discusses results and analysis of this work.

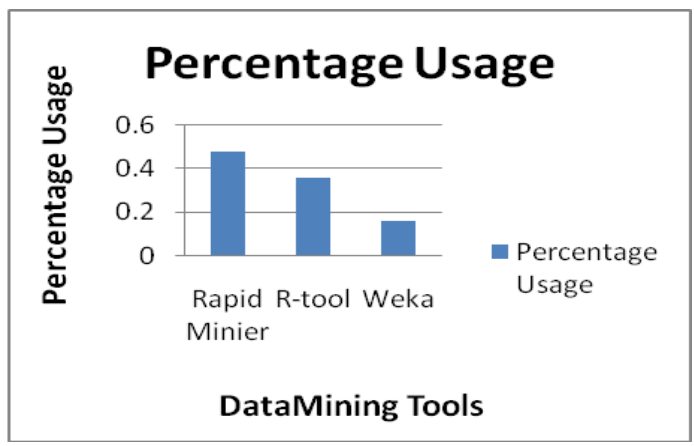

The percentage of usage of Rapid miner is high when comparing with R-tool and Weka.

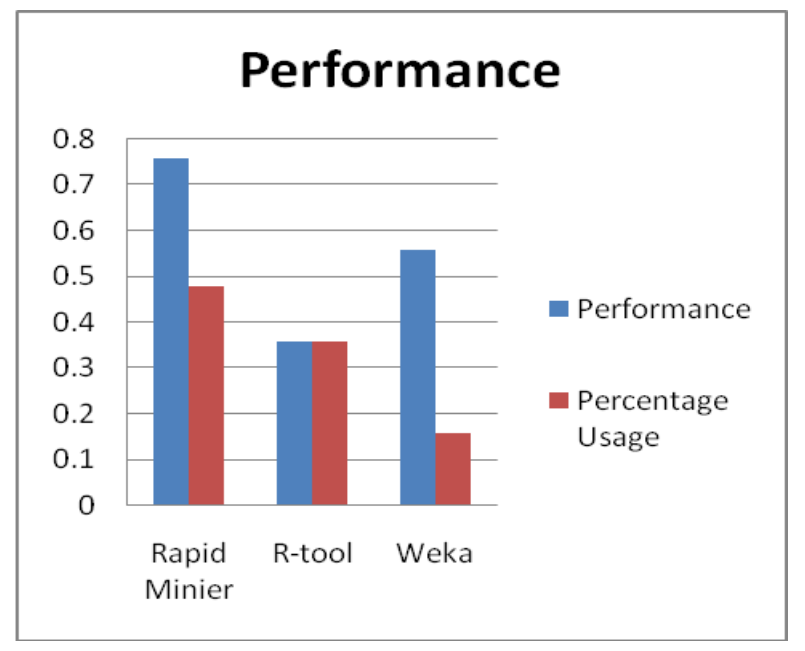

Fig 2: Performance measure of the tool

The performance of the tools are compared along with usage statistics which shows that performance of rapid miner is higher than the R-tool and the Weka

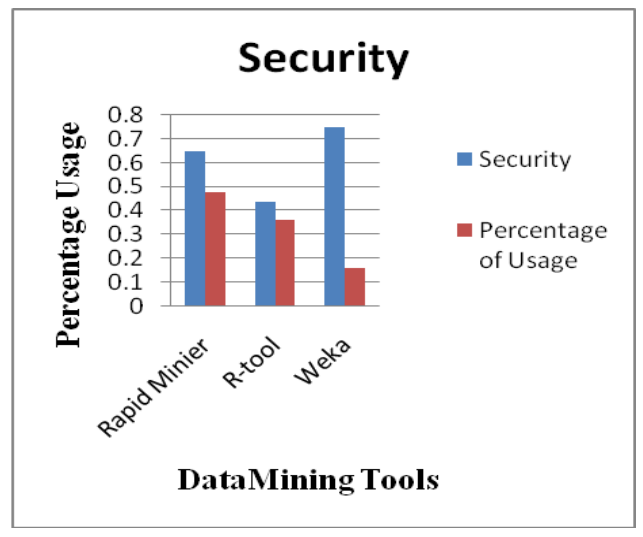

Fig 3 : Security provided by the tools 
When security is concerned Weka is more secured while comparing rapid miner and the R-tool

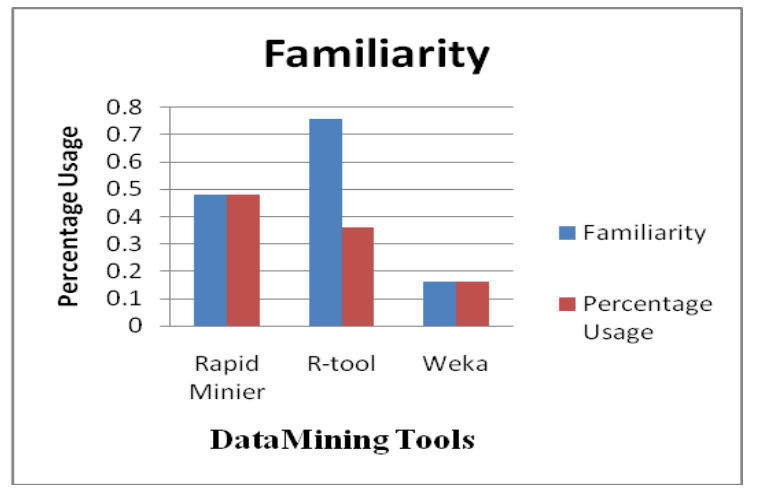

Fig 4: Familiarities of the Tool

As $\mathrm{R}$-Tool is made up of a collection of libraries designed specifically for data science it is more familiar when comparing with other tools.

\section{CONCLUSION}

The objective of the instructional exercise is to acquaint personnel with the bundle and to the academic conceivable outcomes for its utilization in the undergrad software engineering and designing educational plans. The Weka framework gives a rich arrangement of amazing Machine Learning calculations for Data Mining errands, some not found in business information mining frameworks. These incorporate essential measurements and representation apparatuses, just as devices for pre-preparing, characterization, and bunching, all accessible through a simple to utilize graphical UI. Information Mining contemplates calculations and computational ideal models that enable PCs to find structure in databases, perform expectation and determining, and for the most part improve their presentation through cooperation with information. AI is worried about structure PC frameworks that can improve their exhibition in a given area through experience. AI and Data Mining are ending up progressively significant zones of building and software engineering and have been effectively connected to a wide scope of issues in science and designing. As of late, recognizing the significance of these zones in software engineering and building, more work is being done to fuse these territories into the undergrad educational plan. Weka is a broadly utilized bundle that is especially well known for instructive purposes.

\section{. REFERENCES}

[1] Kumaravel A., Rangarajan K.,Algorithm for automaton specification for exploring dynamic labyrinths,Indian Journal of Science and Technology,V-6,I-SUPPL5,PP-4554-4559,Y-2013

[2] P. Kavitha, S. Prabakaran "A Novel Hybrid Segmentation Method with Particle Swarm Optimization and Fuzzy C-Mean Based On Partitioning the Image for Detecting Lung Cancer" International Journal of Engineering and Advanced Technology (IJEAT) ISSN: 2249-8958, Volume-8 Issue-5, June 2019

[3] Kumaravel A., Meetei O.N.,An application of non-uniform cellular automata for efficient cryptography,2013 IEEE Conference on

Information and Communication Technologies, ICT 2013,V-,I-,PP-1200-1205,Y-2013

[4] Kumaravel A., Rangarajan K.,Routing alogrithm over semi-regular tessellations,2013 IEEE Conference on Information and Communication Technologies, ICT 2013,V-,I-,PP-1180-1184,Y-2013

[5] P. Kavitha, S. Prabakaran "Designing a Feature Vector for Statistical Texture Analysis of Brain Tumor" International Journal of Engineering and Advanced Technology (IJEAT) ISSN: 2249-8958, Volume-8 Issue-5, June 2019

[6] Dutta P., Kumaravel A.,A novel approach to trust based identification of leaders in social networks,Indian Journal of Science and Technology,V-9,I-10,PP--,Y-2016

[7] Kumaravel A., Dutta P.,Application of Pca for context selection for collaborative filtering,Middle - East Journal of Scientific Research,V-20,I-1,PP-88-93,Y-2014

[8] Kumaravel A., Rangarajan K.,Constructing an automaton for exploring dynamic labyrinths,2012 International Conference on Radar, Communication and Computing, ICRCC 2012,V-,I-,PP-161-165,Y-2012

[9] P. Kavitha, S. Prabakaran "Adaptive Bilateral Filter for Multi-Resolution in Brain Tumor Recognition" International Journal of Innovative Technology and Exploring Engineering (IJITEE) ISSN: 2278-3075, Volume-8 Issue-8 June, 2019

[10] Kumaravel A.,Comparison of two multi-classification approaches for detecting network attacks, World Applied Sciences Journal,V-27,I-11,PP-1461-1465,Y-2013

[11] Tariq J., Kumaravel A.,Construction of cellular automata over hexagonal and triangular tessellations for path planning of multi-robots,2016 IEEE International Conference on Computational Intelligence and Computing Research, ICCIC 2016,V-,I-,PP--,Y-2017

[12] Sudha M., Kumaravel A.,Analysis and measurement of wave guides using poisson method,Indonesian Journal of Electrical Engineering and Computer Science,V-8,I-2,PP-546-548,Y-2017

[13] Ayyappan G., Nalini C., Kumaravel A., Various approaches of knowledge transfer in academic social network,International Journal of Engineering and Technology,V-,I-,PP-2791-2794,Y-2017

[14] Kaliyamurthie, K.P., Sivaraman, K., Ramesh, S. Imposing patient data privacy in wireless medical sensor networks through homomorphic cryptosystems 2016, Journal of Chemical and Pharmaceutical Sciences 92.

[15] Kaliyamurthie, K.P., Balasubramanian, P.C. An approach to multi secure to historical malformed documents using integer ripple transfiguration 2016 Journal of Chemical and Pharmaceutical Sciences 92.

[16] A.Sangeetha,C.Nalini,"Semantic Ranking based on keywords extractions in the web", International Journal of Engineering \& Technology, 7 (2.6) (2018) 290-292

[17] S.V.GayathiriDevi,C.Nalini,N.Kumar,"An efficient software verification using multi-layered software verification tool "International Journal of Engineering \& Technology, 7(2.21)2018 454-457

[18] C.Nalini,ShwtambariKharabe,"A Comparative Study On Different Techniques Used For Finger - Vein Authentication", International Journal Of Pure And Applied Mathematics, Volume 116 No. 82017 , 327-333, Issn: 1314-3395

[19] M.S. Vivekanandan and Dr. C. Rajabhushanam, "Enabling Privacy Protection and Content Assurance in Geo-Social Networks", International Journal of Innovative Research in Management, Engineering and Technology, Vol 3, Issue 4, pp. 49-55, April 2018.

[20] Dr. C. Rajabhushanam, V. Karthik, and G. Vivek, "Elasticity in Cloud Computing", International Journal of Innovative Research in Management, Engineering and Technology, Vol 3, Issue 4, pp. 104-111, April 2018.

[21] K. Rangaswamy and Dr. C. Rajabhushanamc, "CCN-Based Congestion Control Mechanism In Dynamic Networks", International Journal of Innovative Research in Management, Engineering and Technology, Vol 3, Issue 4, pp. 117-119, April 2018.

[22] Kavitha, R., Nedunchelian, R., "Domain-specific Search engine optimization using healthcare ontology and a neural network backpropagation approach", 2017, Research Journal of Biotechnology, Special Issue 2:157-166

[23] Kavitha, G., Kavitha, R., "An analysis to improve throughput of high-power hubs in mobile ad hoc network" , 2016, Journal of Chemical and Pharmaceutical Sciences, Vol-9, Issue-2: 361-363

[24] Kavitha, G., Kavitha, R., "Dipping interference to supplement throughput in MANET", 2016, Journal of Chemical and Pharmaceutical Sciences, Vol-9, Issue-2: 357-360

[25] Michael, G., Chandrasekar, A.,'Leader election based malicious detection and response system in MANET using mechanism design approach", Journal of Chemical and Pharmaceutical 
Sciences(JCPS) Volume 9 Issue 2, April - June 2016.

[26] Michael, G., Chandrasekar, A.,"Modeling of detection of camouflaging worm using epidemic dynamic model and power spectral density", Journal of Chemical and Pharmaceutical Sciences(JCPS) Volume 9 Issue 2, April - June 2016

[27] Pothumani, S., Sriram, M., Sridhar, J., Arul Selvan, G., Secure mobile agents communication on intranet,Journal of Chemical and Pharmaceutical Sciences, volume 9, Issue 3, Pg No S32-S35, 2016

[28] Pothumani, S., Sriram, M., Sridhar , Various schemes for database encryption-a survey, Journal of Chemical and Pharmaceutical Sciences, volume 9, Issue 3, Pg NoS103-S106, 2016

[29] Pothumani, S., Sriram, M., Sridhar, A novel economic framework for cloud and grid computing, Journal of Chemical and Pharmaceutical Sciences, volume 9, Issue 3, Pg No S29-S31, 2016

[30] Priya, N., Sridhar, J., Sriram, M. "Ecommerce Transaction Security Challenges and Prevention Methods- New Approach" 2016 ,Journal of Chemical and Pharmaceutical Sciences, JCPS Volume 9 Issue 3.page no:S66-S68 .

[31] Priya, N.,Sridhar,J.,Sriram, M."Vehicular cloud computing security issues and solutions" Journal of Chemical and Pharmaceutical Sciences(JCPS) Volume 9 Issue 2, April - June 2016

[32] Priya, N., Sridhar, J., Sriram, M. "Mobile large data storage security in cloud computing environment-a new approach" JCPS Volume 9 Issue 2. April - June 2016

[33] Anuradha.C, Khanna.V, "Improving network performance and security in WSN using decentralized hypothesis testing "Journal of Chemical and Pharmaceutical Sciences(JCPS) Volume 9 Issue 2, April - June 2016.

[34] Anuradha.C, Khanna.V, "A novel gsm based control for e-devices" Journal of Chemical and Pharmaceutical Sciences(JCPS) Volume 9 Issue 2, April - June 2016 .

[35] Anuradha.C, Khanna.V, "Secured privacy preserving sharing and data integration in mobile web environments "Journal of Chemical and Pharmaceutical Sciences(JCPS) Volume 9 Issue 2, April - June 2016 .

[36] Sundarraj, B., Kaliyamurthie, K.P. Social network analysis for decisive the ultimate classification from the ensemble to boost accuracy rates2016 International Journal of Pharmacy and Technology 8

[37] Sundarraj, B., Kaliyamurthie, K.P. A content-based spam filtering approach victimisation artificial neural networks 2016 International Journal of Pharmacy and Technology 83.

[38] Sundarraj, B., Kaliyamurthie, K.P. Remote sensing imaging for satellite image segmentation 2016 International Journal of Pharmacy and Technology $8 \quad 3$

\section{AUTHORS PROFILE}
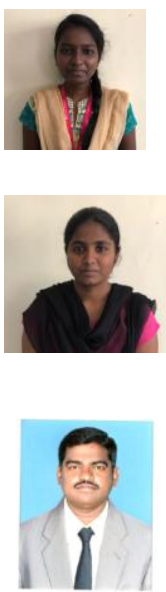

S. Swetha, Student, Department of Information Technology, Bharath Institute of Higher Education and Research, Chennai, India

S. Yogalakshmi, Student, Department of Information Technology, Bharath Institute of Higher Education and Research, Chennai, India

Dr. G. Ayyappan, Assitant Professor, Department of Information Technology, Bharath Institute of Higher Education and Research, Chennai, India 